\title{
Reação de acessos de Capsicum spp. ao fungo Fusarium solani
}

\author{
Isabela Vera dos Anjos ${ }^{1}$, Lucas Pereira da Silva², Lucinéia da Rocha Silva², Kelly Lana Araújo ${ }^{3}$, Ana Flávia Silva \\ Amorim ${ }^{1}$, Marco Antônio Aparecido Barelli ${ }^{3}$, Leonarda Grillo Neves ${ }^{3}$.
}

${ }^{1}$ Mestrandas do Programa de Pós-Graduação em Genética e Melhoramento de Plantas - Universidade do Estado de Mato Grosso (UNEMAT) - Cidade universitária - Av. Santos Dumont, s/n - CEP: 78.200-000, Cáceres, Mato Grosso, Brasil; ${ }^{2}$ Acadêmicos do curso de Agronomia pela Universidade do Estado de Mato Grosso (UNEMAT) - Cidade universitária - Av. Santos Dumont, s/n - CEP: 78.200-000, Cáceres, Mato Grosso, Brasil; ${ }^{3}$ Prof.(a) Dr.(a) da Universidade do Estado de Mato Grosso (UNEMAT) - Cidade universitária - Av. Santos Dumont, s/n - CEP: 78.200000, Cáceres, Mato Grosso, Brasil

Autor para correspondência: Isabela Vera dos Anjos (iveradosanjos@hotmail.com)

Data de chegada: 29/12/2017. Aceito para publicação em: 10/06/2018.

\section{RESUMO}

$10.1590 / 0100-5405 / 189662$

Anjos, I.V.; Silva, L.P.; Silva, L.R.; Araújo, K.L.; Amorim, A.F.S.; Barelli, M.A.A.; Neves, L.G. Reação de acessos de Capsicum spp. ao fungo Fusarium solani. Summa Phytopathologica, v.44, n.4, p.344-349, 2018.

O gênero Capsicum pertencente à família das Solanaceae, é originário da América do Sul sendo cultivado em todo o mundo. As pimentas Capsicum são acometidas por diversas doenças. Dentre estas, destaca-se a podridão do colo, causada pelo fungo Fusarium solani. O presente trabalho foi conduzido com o objetivo de identificar na coleção Capsicum constituída por 18 acessos, fontes de resistência ao patógeno $F$. solani. O experimento foi conduzido em casa de vegetação em delineamento utilizado de blocos casualizados com 18 tratamentos, 3 blocos e 3 plantas por unidade experimental. Para a inoculação foram utilizadas plantas com 51 dias de idade. A metodologia utilizada foi de imersão de raízes com desbaste em uma suspensão de conídios com $1 \times 10^{6}$ conídios/ml pelo período de 24 horas e transplante em substrato comercial. As notas foram transformadas por índice de McKinney, para o cálculo da área abaixo da curva de progresso da doença (AACPD). Os dados foram submetidos a análise de variância e as médias foram agrupadas pelo teste de Scott-Knott e dispersão gráfica. Os acessos resistentes ao patógeno, foram: UNEMAT - 115 (C. frutescens) e UNEMAT- 173 (C.chinense). Os acessos que apresentaram maior suscetibilidade ao patógeno foram; UNEMAT- 134 (C. baccatum var. pendulum) e UNEMAT- 140 (C. frutescens). Conclui-se que há variabilidade genética na coleção quanto à resistência ao patógeno e que a metodologia da imersão (dipping) foi eficaz na discriminação da resistência/suscetiblidade Capsicum spp. ao patógeno.

Palavras-chave: resistência, inoculação, imersão de raízes, doença.

\begin{abstract}
Anjos, I.V.; Silva, L.P.; Silva, L.R.; Araújo, K.L.; Amorim, A.F.S.; Barelli, M.A.A.; Neves, L.G. Reaction of accessions of Capsicum spp. to the fungus Fusarium solani. Summa Phytopathologica, v.44, n.4, p.344-349, 2018.

The genus Capsicum belongs to the family Solanaceae, was originated in the South America and has been cultivated all over the world. Capsicum peppers are affected by several diseases. Among these diseases is collar rot, caused by the fungus Fusarium solani. The present study was conducted with the aim of identifying, in the Capsicum collection constituted of 18 accessions, sources of resistance to the pathogen $F$. solani. The experiment was conducted in a greenhouse, in a randomized block design with 18 treatments, 3 blocks and 3 plants per experimental unit. For inoculation, 51-day-old plants were used. The adopted methodology was root immersion with thinning in a conidial suspension of $1 \times 10^{6}$ conidia / $\mathrm{ml}$ for the period of 24 hours and transplantation in commercial

substrate. The scores were transformed by using McKinney's index to calculate the area under the disease progress curve (AUDPC). The data were subjected to analysis of variance and means were grouped according to Scott-Knott test and graphic dispersion. Accessions resistant to the pathogen were: UNEMAT - 115 (C. frutescens) and UNEMAT - 173 (C.chinense). Accessions that presented greater susceptibility to the pathogen were: UNEMAT-134 (C. baccatum var. Pendulum) and UNEMAT-140 (C. frutescens). We can conclude that there is genetic variability in the collection regarding resistance to the pathogen and that the methodology of dipping was effective in discriminating between resistance / susceptibility of Capsicum spp. to the pathogen.
\end{abstract}

Keywords: resistance, inoculation, root immersion, disease.

O gênero Capsicum pertencente à família Solanaceae (13) é originário da América do Sul, posteriormente as pimentas do gênero espalharam-se por todo o trópico americano $(2,10)$. Durante o período de descobrimento das Américas as pimentas do gênero Capsicum destacaram-se, por apresentarem maior pungência (14). Foram então disseminadas por toda a Europa e pelo mundo de forma rápida (12).

As pimentas Capsicum tornaram-se destaque entre a família das solanáceas pelo fato de sua exploração normalmente ocorrer por meio de agricultures familiares que impulsionou esta popularidade (5). Existem cinco espécies que são domesticadas sendo três amplamente cultivadas: Capsicum annuum (pimentão), Capsicum chinense (tipos diversos), Capsicum frutescens (malaguetas). Enquanto Capsicum baccatum (dedo de moça e outras) e Capsicum pubescens (rocoto), são predominantemente confinadas ao cultivo na América Latina $(2,10,13)$.

Sabe-se que as pimentas do gênero Capsicum são acometidas por diversas doenças (6). Os estudos sobre essas doenças, seus impactos na produção e medidas de manejo são escassos no Brasil (3). Existem atualmente diversos estudos nesta linha, visando à descoberta de fontes de resistência (16). Por exemplo o trabalho de Babu et al. (1) em que investigou fontes de resistência em Capsicum spp. contra uma gama de problemas fitossanitários. Desta forma, faz-se necessário uma investigação ampla do comportamento das espécies de Capsicum spp. 
e níveis de resistência a doenças.

Dentre as doenças que atualmente acometem as pimentas do gênero Capsicum spp., destacam-se a murcha causada por Fusarium (11) Segundo Tembhurne et al. (17), a murcha causada por Fusarium solani (Mart.) Sacc. tem causado grandes problemas na produção de pimentas.

O presente trabalho foi conduzido com o objetivo de investigar fontes de resistências ao fungo de solo Fusarium solani. em uma coleção de trabalho de Capsicum spp. constituída por 18 genótipos com potencial para alto teor de antioxidante e resistência a antracnose.

\section{MATERIAL E MÉTODOS}

\section{Área de estudo}

O estudo foi realizado em casa de vegetação com condições controladas, no campo experimental da Universidade do Estado de Mato Grosso (UNEMAT) - Campus Cáceres, sob responsabilidade do Laboratório de Melhoramento Genético Vegetal da UNEMAT. O experimento de avaliação de resistência foi realizado nos meses de Julho a Agosto de 2017. O município de Cáceres está localizado entre as latitudes $15^{\circ} 27^{\prime}$ e $17^{\circ} 37^{\prime} \mathrm{S}$ e as longitudes $57^{\circ} 00^{\prime}$ e $58^{\circ} 48^{\prime} \mathrm{O}$, à uma altitude de $118 \mathrm{~m}$, possui clima tropical quente e úmido com inverno seco (Awa) clima segundo classificação de Köppen (8).

A coleção de trabalho é composta por 18 acessos selecionados do Banco Ativo de Germoplasma (BAG) do Laboratório de Melhoramento Genético Vegetal da UNEMAT. A seleção ocorreu com base em estudos anteriores, selecionando acessos com potencial para alto teor de antioxidante e resistência a antracnose, estes estão listados na Tabela 1.

Metodologia de inoculação de Fusarium solani

Tabela 1. Coleção de trabalho de acessos de Capsicum spp.

\begin{tabular}{|c|c|}
\hline Acessos & Espécies \\
\hline UNEMAT 17 & \multirow{6}{*}{ Capsicum frutescens (malagueta) } \\
\hline UNEMAT 44 & \\
\hline UNEMAT 51 & \\
\hline UNEMAT 113 & \\
\hline UNEMAT 115 & \\
\hline UNEMAT 140 & \\
\hline UNEMAT 39 & \multirow{6}{*}{ Capsicum chinense (pimentas de cheiro) } \\
\hline UNEMAT 56 & \\
\hline UNEMAT 117 & \\
\hline UNEMAT 118 & \\
\hline UNEMAT 122 & \\
\hline UNEMAT 173 & \\
\hline UNEMAT 105 & \multirow{3}{*}{$\begin{array}{l}\text { Capsicum baccatum var. pendulum (dedo } \\
\text { de moça) }\end{array}$} \\
\hline UNEMAT 134 & \\
\hline UNEMAT 151 & \\
\hline UNEMAT 2 & \multirow{3}{*}{ Capsicum annuum (pimentão) } \\
\hline UNEMAT 116 & \\
\hline UNEMAT 163 & \\
\hline
\end{tabular}

As sementes dos 18 acessos foram dispostas em bandejas poliestireno expandido de 128 células, contendo substrato comercial Plantimax ${ }^{\circledR}$. As bandejas permaneceram em casa de vegetação. Após a germinação das sementes foram realizadas aplicações nas plântulas de adubo foliar semanalmente, as mudas permaneceram em bandejas por 51 dias após a semeadura.

A inoculação das raízes das plântulas foi realizada aos 51 dias da semeadura. As mudas foram retiradas de suas células, e tiveram seu sistema radicular lavado em água corrente. Cada plântula sofreu um corte de aproximadamente $2 \mathrm{~cm}$ de suas raízes, como ferimento. Em seguida foram então imersas em $5 \mathrm{ml}$ de suspensão de conídios na concentração de $1.0 \times 10^{6}$ conídios $/ \mathrm{ml}$ por um período de 24 horas, posteriormente foram transplantadas para copos plásticos com capacidade de $700 \mathrm{~mL}$ contendo solo, areia e substrato na proporção de $2: 1: 1$, conforme Figura 1.

A avaliação foi realizada a partir do aparecimento dos primeiros sintomas por meio de escala de notas adaptada de (9), variando de 1 a 5 , onde: $1=$ ausência de sintomas; $2=$ planta com $1 / 3$ das folhas murchas; $3=$ planta $2 / 3$ das folhas murchas; $4=$ planta totalmente murcha e $5=$ planta morta; e período de sobrevivência.

$\mathrm{O}$ experimento foi realizado em delineamento de blocos casualizados (DBC) com 18 tratamentos, 3 blocos, 3 plantas por unidade experimental. Ao final das avaliações as notas foram transformadas por índice de McKinney (7), para o cálculo da área abaixo da curva de progresso da doença (AACPD) (15). Os dados foram submetidos a análise de variância e as médias foram agrupadas pelo teste de ScottKnott a 5\% de probabilidade e dispersão gráfica. As análises foram realizadas com o programa computacional Genes v.2016.6.15. Para confirmação da inoculação, foi realizado postulados de Koch.

\section{RESULTADOS E DISCUSSÃO}

O experimento foi avaliado por um período de 39 dias, com a realização de visitas diárias onde foi possível verificar que os primeiros sintomas o aparecimento de sintomas característicos da doença, como necrose no colo (Figura 2), murcha, queda de folhas e o não desenvolvimento das raízes a partir de 11 dias (Figura 3).

De acordo com os dados obtidos, os 18 acessos de Capsicum spp. foi observada variação entre os genótipos quanto aos níveis de resistência ao F. solani, pela área abaixo da curva de progresso da doença (AACPD) e para período de sobrevivência (PS).

A análise de variância (Tabela 2) demonstrou diferença significativa entre as espécies, a $1 \%$ de probabilidade, pelo teste $\mathrm{F}$, para a variável $\mathrm{AACPD}$, e a $5 \%$ de probabilidade, pelo teste $\mathrm{F}$, para o variável período de sobrevivência As médias foram agrupadas pelo teste de Scott-Knott a $5 \%$ de probabilidade (Tabela 3 ).

Posteriormente, foi possível realizar o agrupamento destes acessos, por meio de Dispersão Gráfica. Conforme apresentado na Figura 4, os acessos da coleção de trabalho, agruparam-se em 3 grupos, de forma que foi possível visualizar as variações de níveis de resistência dos acessos entre resistentes, intermediários e suscetíveis.

Os acessos da coleção de trabalho, que se apresentaram resistentes à inoculação de F. solani foram os acessos: UNEMAT 115 - Capsicum frutescens e UNEMAT 173 - Capsicum chinense, estes acessos não apresentaram sintomas e morte de plantas, conforme a Figura 5. As plantas mantiveram-se resistentes durante a o período de realização do experimento, que ocorreu durante 39 dias. Estatisticamente pelo teste Scott-Knott, outros genótipos também foram considerados resistentes, entretanto alguns sintomas foram observados durante o período de 

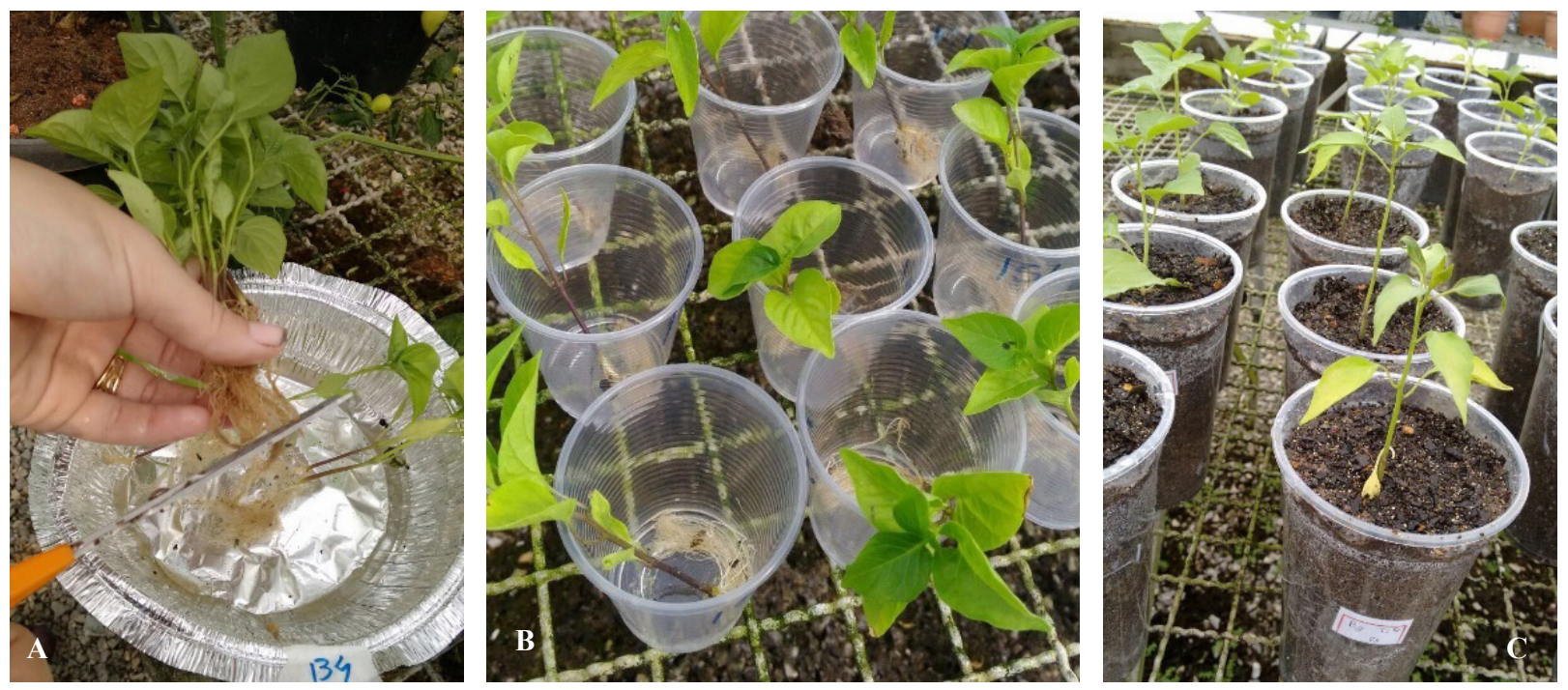

Figura 1. Passo a passo da inoculação de Fusarium solani em mudas Capsicum spp. pelo método da imersão de raízes em suspensão de conídios e replantio em copos.
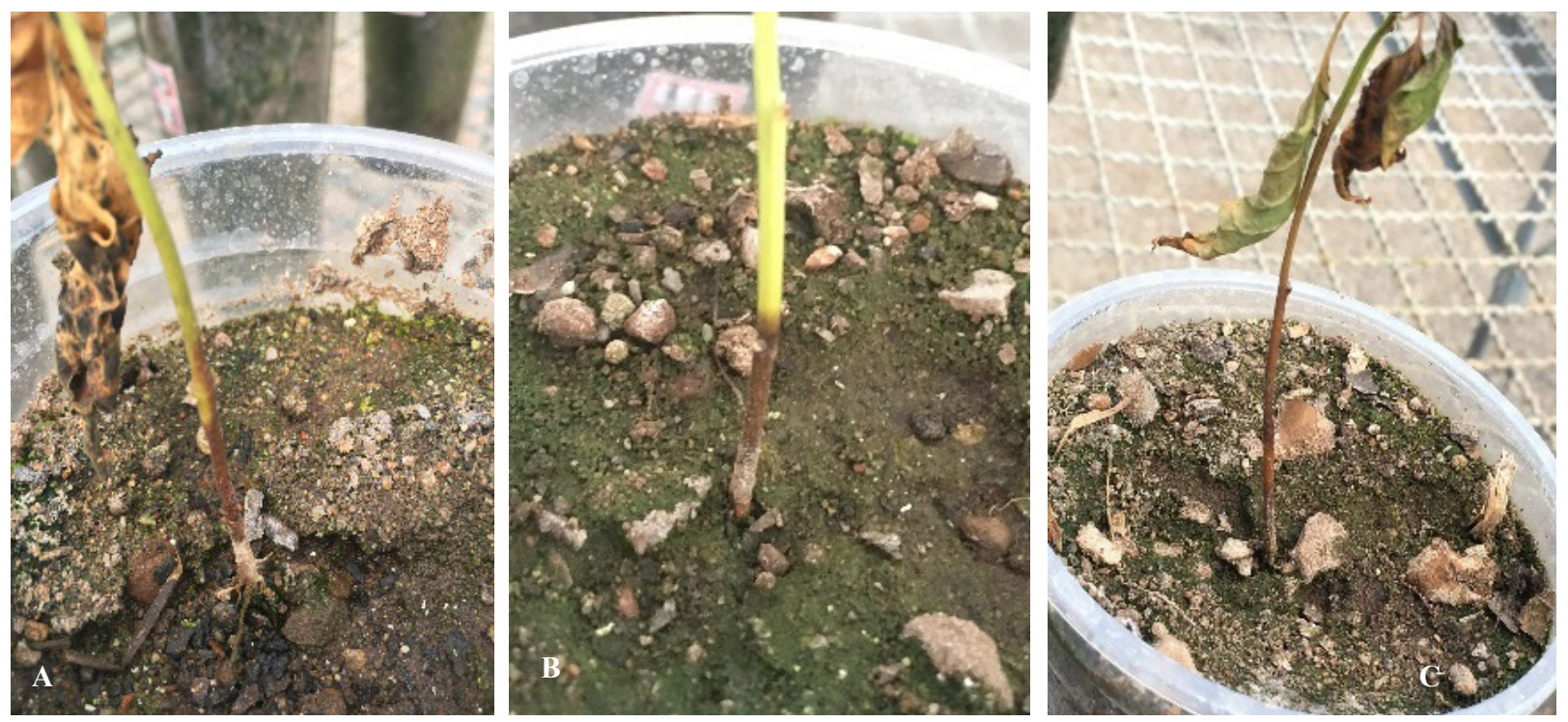

Figura 2. A, B e C) Sintomas de necrose no colo de plantas suscetíveis de Capsicum spp. inoculadas com Fusarium solani.
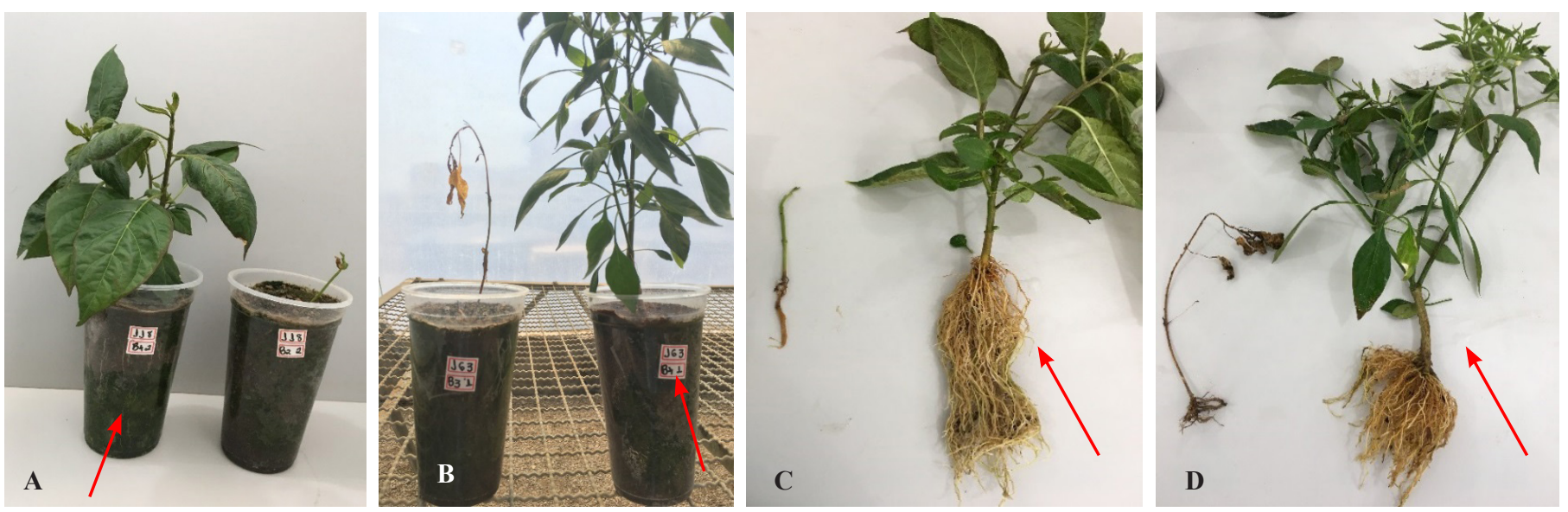

Figura 3. Plantas de Capsicum spp. inoculadas com Fusarium solani comparadas com a testemunha. A-C) Planta inoculada e testemunha, setaevidenciando a testemunha Acesso UNEMAT - 118; B-D) planta inoculada e testemunha, seta- evidenciando as testemunhas. Acesso UNEMAT- 163. 
Tabela 2. Resumo da análise de variância das características de resistência de 18 genótipos de Capsicum spp. quanto a F. solani

\begin{tabular}{|c|c|c|c|}
\hline \multirow[t]{2}{*}{ Fonte de variação } & \multirow{2}{*}{ G.L } & \multicolumn{2}{|c|}{ QM } \\
\hline & & AACPD & PS \\
\hline Blocos & 2 & 268245,8848 & 54,6852 \\
\hline Genótipos & 17 & $* * 547903,4737$ & * 62,4009 \\
\hline Resíduos & 34 & 161269,8499 & 30,6656 \\
\hline
\end{tabular}

(**) Significativo a 1\%, (*) Significativo a 5\%, pelo teste F; AACPD - Área abaixo da curva de progresso da doença, PS - Período de sobrevivência.

Tabela 3. Médias dos genótipos que apresentaram diferenças significativas pelo teste F, agrupados pelo teste Scott e Knott (5\% de probabilidade).

\begin{tabular}{|c|c|c|c|c|}
\hline \multirow{2}{*}{$\frac{\text { Genótipos }}{\text { (UNEMAT }-115 \text { (C. frutescens }}$} & \multicolumn{2}{|c|}{ AACPD } & \multicolumn{2}{|c|}{ PS } \\
\hline & 675,5556 & $\mathrm{a}$ & 39 & $\mathrm{a}$ \\
\hline (UNEMAT - 117 (C. chinense & 1113,333 & a & 36,6667 & $\mathrm{a}$ \\
\hline (UNEMAT - 44 (C. frutescens & 1332,222 & $\mathrm{a}$ & 37 & $\mathrm{a}$ \\
\hline (UNEMAT - 163 (C. annuum & 1373,333 & $\mathrm{a}$ & 36,3333 & $\mathrm{a}$ \\
\hline (UNEMAT - 116 (C. annuum & 1465,556 & $\mathrm{a}$ & 31,3333 & $\mathrm{a}$ \\
\hline (UNEMAT - 105 (C. baccatum var. pendulum & 1486,667 & $\mathrm{a}$ & 32,3333 & $\mathrm{a}$ \\
\hline (UNEMAT - 39 (C. chinense & 1724,444 & $\mathrm{~b}$ & 30,6667 & $\mathrm{a}$ \\
\hline (UNEMAT - 51 (C. frutescens & 1795,556 & $\mathrm{~b}$ & 30,3333 & $\mathrm{a}$ \\
\hline (UNEMAT - 17 (C. frutescens & 1811,111 & $\mathrm{~b}$ & 30 & $\mathrm{a}$ \\
\hline (UNEMAT - 113 (C. frutescens & 1848,889 & $\mathrm{~b}$ & 32,3333 & $\mathrm{a}$ \\
\hline (UNEMAT - 122 (C. chinense & 1877,778 & $\mathrm{~b}$ & 28,6667 & $\mathrm{a}$ \\
\hline (UNEMAT - 56 (C. chinense & 1916,667 & $\mathrm{~b}$ & 28,6667 & $\mathrm{a}$ \\
\hline
\end{tabular}

AACPD - Área abaixo da curva de progresso da doença, PS - Período de sobrevivência.

avaliação.

Enquanto o genótipo que apresentou maior suscetibilidade à inoculação de $F$. solani foi o UNEMAT 134 (C. baccatum var. pendulum), apresentou sintomas mais precoces, registrando morte de plantas com 19 dias após a inoculação.

Os outros 15 acessos apresentaram níveis de resistência intermediários, onde 5 acessos de $C$. frutescens, 5 de $C$. chinense, 2 de

(AC
C. baccatum var. pendulum e 3 acessos de C. annuum, as plantas destes acessos sobreviveram por um período de 30 a 36 dias aproximadamente.

De acordo com os resultados obtidos, ficou provado que a metodologia de inoculação de plantas de Capsicum spp. por imersão de raízes com corte, para o patógeno Fusarium solani foi eficiente na discriminação da suscetibilidade de Capsicum ao patógeno .

Resultados semelhantes foram encontrados por Castro (4) quando avaliou diferentes metodologias de inoculação e concluiu que para a 


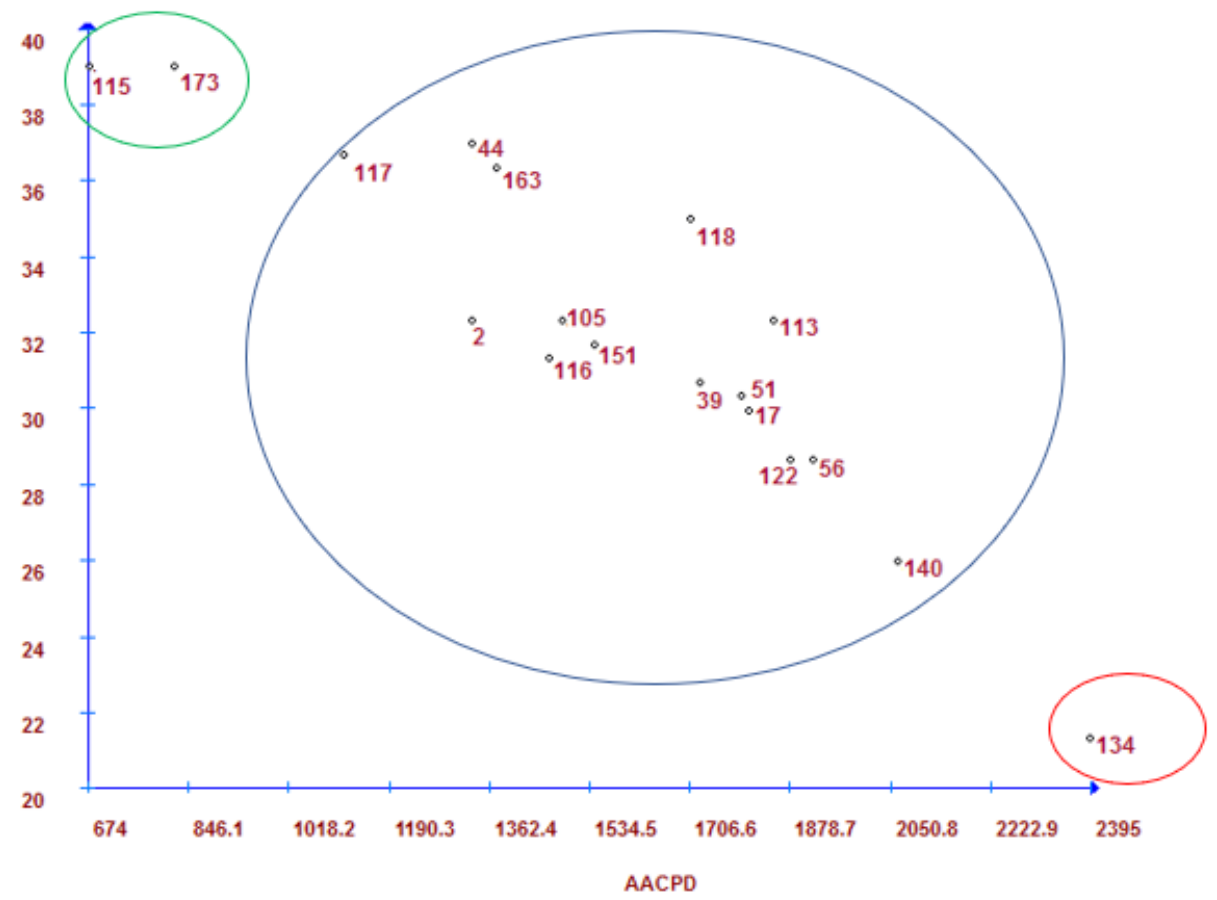

Figura 4. Dispersão gráfica da avaliação do comportamento de 18 genótipos de Capsicum spp. em relação ao fungo Fusarium solani por meio AACPD - Área abaixo da curva de progresso da doença, PS - Período de sobrevivência.
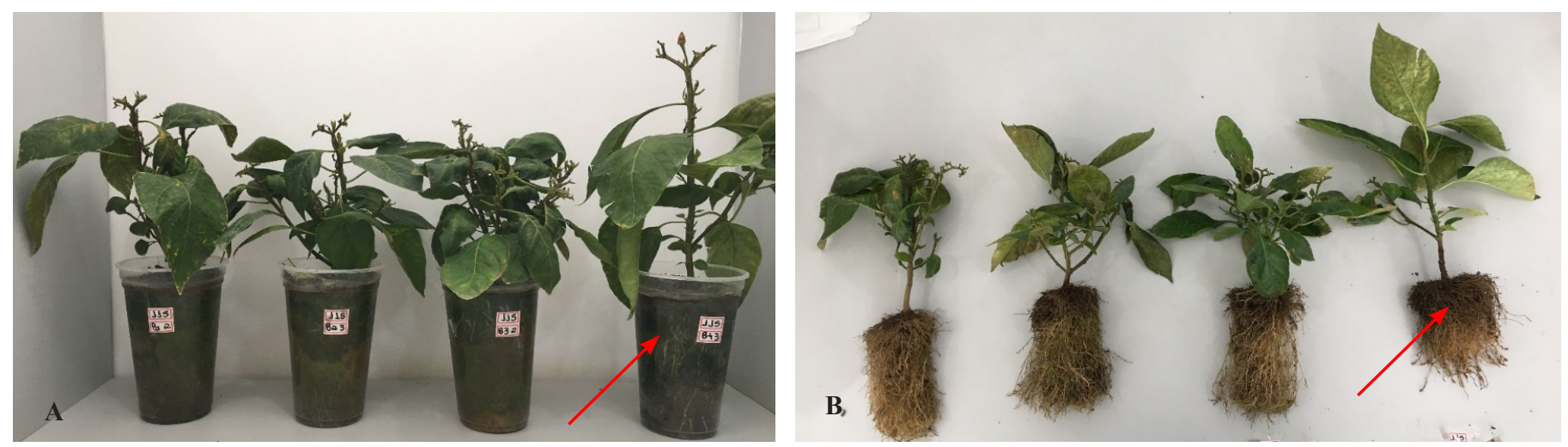

Figura 5. Comparação entre as plantas de um acesso UNEMAT -115 de Capsicum considerado resistente com 3 repetições e 1 testemunha A e B) Acesso UNEMAT-115, plantas inoculadas, seta- evidenciando a planta testemunha.

inoculação de Fusarium spp. em espécies de Capsicum, a metodologia de imersão de raízes com corte foi a que demonstrou maior eficácia. Outros autores como Tembhurne et al. (17) também utilizaram com sucesso desta metodologia de inoculação, em seu trabalho de investigação de genótipos de C. annuum resistentes a $F$. solani.

Tendo em vista que o patógeno é facilmente disseminado por detritos vegetais e solo, e seu difícil controle, a utilização de genótipos resistentes possibilita mitigar a ocorrência da doença torna-se uma alternativa viável.

\section{CONCLUSÕES}

Verificou-se a eficácia da metodologia de inoculação de Fusarium solani, por imersão de raízes com corte em plantas de Capsicum spp.. Foi possível constatar a existência de variabilidade genética entre e dentro das espécies de Capsicum spp. da coleção quanto a resistência ao fungo Fusarium solani. Os genótipos que se apresentaram resistentes foram os acessos UNEMAT 115 - Capsicum frutescens e UNEMAT 173 - Capsicum chinense.

\section{AGRADECIMENTOS}

Agradecemos a FAPEMAT - Fundação de Amparo a Pesquisa do Estado de Mato Grosso, pelo auxílio financeiro ao projeto de pesquisa desenvolvido. 


\section{REFERÊNCIAS}

1. Babu, S. B.; Pandravada, S. R.; Prasada Rao, R. D. V. J.; Anitha, K.; Chakra -Barty, S. K.; Varaprasad, K. S. Global sources of pepper genetic resources against arthropds, nematodes and pathogens. Crop Protection, Guildford, v.30, p.389-400, 2011.

2. Barbieri, R.L., Heiden, G., Neitzke, R.S., Choer, E., Leite, D.L. and Garrastazú, M.C. Capsicum Gene Bank of Southern Brazil. Acta Horticulturae, Wageningen. v.745, 319-322, 2007. Disponível em: $<$ https://doi. org/10.17660/ActaHortic.2007.745.17>. Acesso em: 18 dez. 2017.

3. Carmo, M. G. F.; Zerbini Junior, F. M.; Maffia, L. A. Principais doenças da cultura da pimenta. Informe Agropecuário- EPAMIG, Belo Horizonte. v. 27, n. 235, 87-98, 2006.

4. Castro, D.C.C. Búsqueda de resistencia a la pudrición causada por $\boldsymbol{F} \boldsymbol{u}$ sarium spp. en Capsicum. 2014, 89 p. (Dissertação - Mágister em Ciências Agrárias). Universidad Nacional De Colômbia, Colômbia.

5. Freitas R. D.; Laurindo B. S.; Seus R.; Rodrigues A. F. S.; Pereira N. E.; Silva D. J. H. Origem e período de coleta de acessos de Capsicum sp. do BGH - UFV. Horticultura Brasileira, Brasília. v.30, S4701-S4707, 2012. Disponível em: http://www.abhorticultura.com.br/eventosx/trabalhos/ev_6/ a5143_t7815_comp.pdf>. Acesso em: 18 dez. 2017.

6. Lopes, C. A.; Henz, G. P.; Reis, A. Doenças das pimentas e seu controle. In: Rêgo, E. R.; Finger, F. L.; Rêgo, M. M. Produção, genética e melhoramento de pimentas (Capsicum spp.). Recife: Imprima, 2011. p53-65.

7. McKinney, H.H. Influence of soil, temperature and moisture on infection of wheat seedlings by Helminthosporium sativum. Journal of Agricultural Research, Washington, v.26, p.195-217,1923.

8. Neves, S. M. A. S., Nunes, M. C. M., Neves, R. J. Caracterização das condições climáticas de Cáceres/MT-Brasil, no período de 1971 a 2009: subsídio às atividades agropecuárias e turísticas municipais. Boletim Goiano de Geografia, Goiânia. v.31, n.2, 55-68, 2011. Disponível em: < http:// www.redalyc.org/html/3371/337127156004/>. Acesso em: 18 dez. 2017.

9. Nielsen, L. W.; Haynes, F. L. Resistance in Solanum tuberosum to Pseudomonas solanacearum. American Journal of Potato Research, New York, v. 37, n. 8, p. 260-267, 1960. Disponível em: <https://doi.org/10.1007/ BF02855800>. Acesso em: 18 dez. 2017.

10. Pickersgill, B. Genetic resources and breeding of Capsicum spp. Euphytica, Wageningen. v. 96, n. 1, p.129-133, 1997. Disponível em: < https://doi. org/10.1023/A:1002913228101>. Acesso em: 18 dez. 2017.

11. Raghu, S.; Benagi, V. I.; Nargund, V. B. Cultural, morphological and pathogenic variability among the isolates of Fusarium solani causing wilt disease of Chilli (Capsicum annuum L.). Journal of Pure and Applied Microbiology, Shahjahanabad, v.10, n.1, p. 599-604, 2016.

12. Rêgo, E. D., Finger, F. L., Nascimento, N. D., Araújo, E. R., Sapucay, M. J. L. C. Genética e melhoramento de pimenteiras Capsiscum spp. In: Rêgo, E. R., Finger, F. L., Rêgo, M. M. Produção, genética e melhoramento de pimentas, 117-136p. Recife: Imprima, 2011.

13. Reifschneider, F. J. B.; Nass, L. L.; Heinrich, A. G.; Henz, G.P.; Ribeiro, C. S. C.; Henz. G. P.; Euclides Filho, K.; Boiteux, L. S.; Ritschel, P.; Ferraz, R. M; Quecini, V. Uma pitada de biodiversidade na mesa dos brasileiros. Pimentas. Brasília, DF. 156 p. 2014. Disponível em: <https://issuu. com/cica/docs/uma_pitada_de_biodiversidade>. Acesso em: 18 dez. 2017.

14. Ribeiro C. S. C.; Reifschneider F. J. B. Genética e Melhoramento. In: Ribeiro C.S.C.; Carvalho S.I.C.; Henz G.P.; Reifschneider F.J.B. Pimentas Capsicum. Brasília: Embrapa Hortaliças. p. 55-69. 2008.

15. Shaner, G., Finney, R.E. The effect of nitrogen fertilization on the expression of slow-mildewing resistence in knox wheat. Phytopathology, Athens. 67 (8):1051-1056. 1977.

16. Soares, J. V. C.; Bentes, J. L. S.; Gasparotto, L. Reaction of Capsicum spp. genotypes to stem rot (Sclerotium rolfsii). Summa Phytopathologica, Botucatu, v. 43, n.1, p. 58-59, 2017. Disponível em: <http://dx.doi. org/10.1590/0100-5405/2182>. Acesso em: $18 \mathrm{dez} .2017$.

17. Tembhurne, B.V.; Belabadevi, B.; Kisan, B.; Tilak, I.S.; Ashwathanarayana, D.S.; Suvarna, Nidagundi And Naik, M.K. 2017. Molecular Characterizae tion and Screening for Fusarium (Fusarium solani) Resistance in Chilli (Capsicum annuum L.) Genotypes. International Journal of Current Microbiology and Applied Science, Tamilnadu, v.6, n.9, 1585-1597p. Disponível em: $<$ https://doi.org/10.20546/ijcmas.2017.609.195>. Acesso em 18 dez. 2017. 